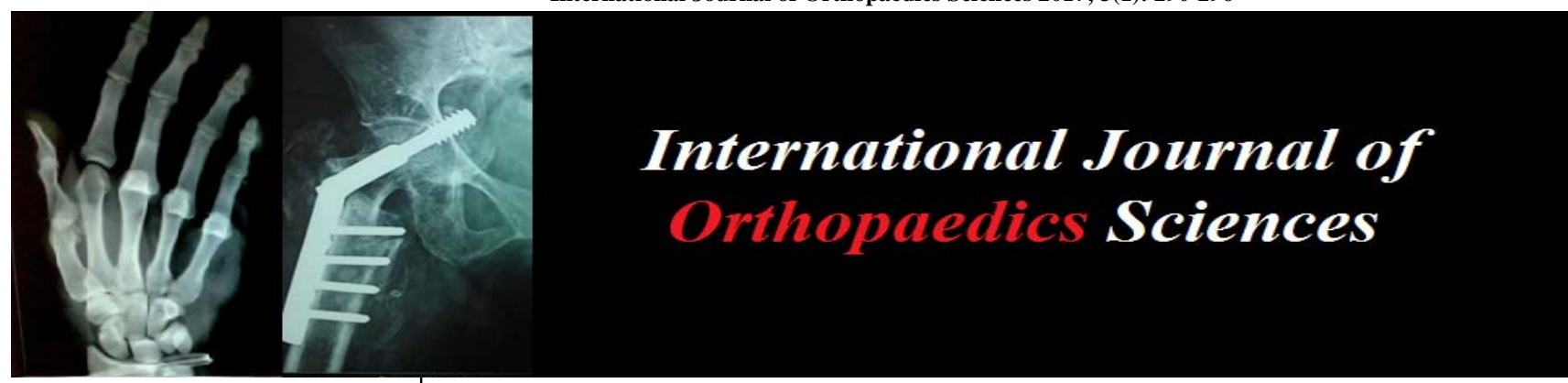

ISSN: 2395-1958

IJOS 2017; 3(1): 290-296

(C) 2017 IJOS

www.orthopaper.com

Received: 16-11-2016

Accepted: 17-12-2016

Vidyadhar S Donimath

Associate Professor

Orthopaedics department

Karnataka Institute of Medical

Sciences, Hubli, Karnataka,

India

Rahul Desai

Post-graduate, Orthopaedics

Department, Karnataka

Institute of Medical Sciences,

Hubli, Karnataka, India
Correspondence

Vidyadhar S Donimath

Associate Professor

Orthopaedics department

Karnataka Institute of Medical

Sciences, Hubli, Karnataka,

India

\section{Surgical management of open tibial shaft fractures in adults by reamed versus unreamed intramedullary interlocking nailing: A comparative study}

\section{Vidyadhar S Donimath and Rahul Desai}

DOI: $\underline{\text { http://dx.doi.org/10.22271/ortho.2017.v3.i1e.46 }}$

\section{Abstract}

Back ground and objectives: Tibial diaphyseal fractures are one of the commonest long bone fractures encountered by most of the orthopaedic surgeons. Because most of the length of tibia is subcutaneous throughout, open fractures are more common in tibia than in any other major long bone. Because of high prevalence of complications associated with these fractures, management is often is difficult and the optimum method of treatment remains a subject of controversy. This prospective study was conducted at the department of orthopaedics, KIMS Hubli to evaluate and compare the results of closed interlocking intramedullary nailing with and without reaming in the treatment of the open fractures of mid shaft tibia in adults. It was done to compare the efficiency of interlocking intramedullary nailing with and without reaming in treatment of open fractures of mid shaft tibia with other studies in terms of time required for union, rate of malunion and malrotation, rate of infection and range of motion of ankle and knee joint.

Materials and methods: This study was done on 50 patients between the age group of 25-40yrs admitted under Department of Orthopaedics of Karnataka Institute of Medical Sciences Hospital, Hubli with open fractures mid shaft of tibia selected based on inclusion \& exclusion criteria during the period from $1 / 08 / 2013$ to $31 / 07 / 2015$ treated surgically using reamed/unreamed intramedullary interlocking nailing. Of the 50 patients 25 were treated by reamed and 25 by unreamed intramedullary interlocking nailing. All the cases were fresh fractures and traumatic in nature. They were done with the procedure as early as possible and the secondary procedures were done when needed. The cases were followed up for an average period of 6-9 months. None of the cases were lost to follow up.

Results: Open fractures of the tibial shaft managed with or without reamed interlocked intramedullary nailing gave good functional results and patient satisfaction It involves minimal surgical trauma and less blood loss. It provides the advantages of early ambulation, lower rates of infection, delayed union, non union and malunion compared to other treatment modalities. It provides with early weight bearing and earlier returns to work. In our series, the overall functional outcome according to Johner and Wruhs' criteria is equal and there is no significant difference in both reamed and unreamed nailing in open tibial shaft fractures in adults.

Interpretation and conclusions: Intramedullary nailing is one of the methods of treatment for open tibial shaft fractures in adults, despite the fact that controversy exists regarding the choice of reamed or unreamed intramedullary nailing. There are no clear indications or contraindications for choosing either option. Clinical and radiographic results of nailing after reaming are similar to those of nailing without reaming for fixation of open fractures of the tibial shaft. The over-all functional outcome according to the Johner and Wruhs' criteria was similar between the two groups, with no evidence that reaming delays the process of union. Considering the ease of performing the technique and the decreased operative time, unreamed interlocking nailing may have an edge over reamed interlocking nailing.

Keywords: Closed interlocking intramedullary nailing, reamed, unreamed, open fractures

\section{Introduction}

"The primary objective in the management of an open fracture is union with prevention or eradication of wound sepsis."- Gustillo et al. Fractures of the tibia and fibula shaft are the most common long bone fractures. In an average population; there are about 26 tibial diaphyseal fractures per 100,000 populations per year. Men are more commonly affected than women, with the male incidence being about 41 per 100,000 per year and the female incidence about 12 per 100,000 per year ${ }^{[1]}$.

Fractures of the shaft of the tibia cannot be treated by following a simple set of rules, because One third of the tibial surface is subcutaneous throughout most of its length, open fractures are 
more common in the tibia than in any other major long bone. The blood supply to the tibia is more precarious than that of bones enclosed by heavy muscles ${ }^{[2]}$. High-energy tibial fractures may be associated with compartment syndrome or neurovascular injury. There are five principle causes of tibial diaphyseal fractures; falls, sports injuries, direct blows or assaults, motor vehicle accidents and gunshot injuries ${ }^{[1]}$.

The various modalities of treatment are- Conservative gentle manipulation and use of long leg cast (Sarmiento's technique), Open reduction and internal fixation with plates and screws, intramedullary fixation (including Enders nail, intramedullary non-locked V-nails, and interlocking intramedullary nails with or without reaming), external fixation techniques. The surgeon should be capable of using all these techniques and must weigh advantages and disadvantages of each one and adapt the best possible treatment. The best treatment should be determined by a thoughtful analysis of morphology of the fracture, the amount of energy imparted to the extremity, the quality of the bone, the age and general conditions of the patient and most importantly the status of the soft tissues. The goals of surgical management include-correction and maintenance of sagital and coronal alignment, restoration of length and rotation, early functional knee and ankle range of motion, the prevention of infection, the achievement of bony union. The author (Charley J) in his text said that he believed the eventual solution to the tibial fractures would be an intramedullary nail ${ }^{3}$.The intramedullary nailing locked or unlocked has become an attractive option since image intensifier has made closed intramedullary nailing possible. Nail is a load sharing device and is stiff to both axial and torsional forces. Closed nailing involves least disturbance of soft tissue, fracture hematoma and natural process of bone healing as compared to other forms of internal fixation. Intramedullary nails such as Lottes and Ender nails used without reaming have been employed successfully in the treatment of open tibial fractures and have been associated with low rates of post-operative infection. They are however contraindicated for communited fractures as there tends to be shortening or displacement of such fractures around these small nails $[4,5]$. The locking of intramedullary nails to the major proximal and distal fragments decreases the prevalence of malunion and non-union of communited fractures. In unreamed nailing, there is less risk of fat embolism and several studies suggest better preservation and more-rapid recovery of the intraosseous blood supply after insertion of a smalldiameter nail ${ }^{[6]}$. Some studies also reported a lower risk of infection in unreamed nailing due the fact that there is less disruption of the endosteal blood supply and the time for surgery is lesser as compared to reamed nailing. In contrast, some studies seem to indicate that delayed union and nonunion occur more frequently with unreamed nailing. Some studies indicate increased incidence of nail and screw breakage with unreamed nailing ${ }^{[7]}$. There was a high incidence of the need for a further operation and a high rate of failure of the implants in the unreamed studies as compared with the reamed studies. Intramedullary nailing with reaming of the medullary canal is generally considered to cause the damage to the endosteal blood supply, which may thereby increase the risks of deep infection and non-union. It has, therefore, been suggested that insertion of nails without reaming is safer. The rate of infection after treatment of open tibial fractures with intramedullary nailing with reaming has been relatively high, causing most investigators to discourage the use of this technique for grade II and III open tibial fractures. But some studies suggest that reaming can help to fix the fracture with a larger size nail thus achieving better stability and thus help in early union rates and less chances of implant failure. The need for a second procedure is lower as compared to the unreamed cases. Recent studies however have indicated that nailing with or without reaming can be used for open tibial fractures with equal results of union in either method ${ }^{8}$.Many randomized controlled trials have been undertaken to compare the reamed and unreamed intramedullary nailing for the treatment of open tibial shaft fractures, but the clinical advantages and disadvantages of these two methods remain under debate. There is a need to systematically review the available evidence for these two methods of intramedullary nailing so as to make an optimal treatment of choice. This led us to design a trial, to study the results of closed interlocking intramedullary nailing with and without reaming in the treatment of open tibial shaft fractures in adults.

\section{Materials and methods}

The present study was undertaken at the department Orthopedics, Karnataka Institute of Medical Sciences after obtaining ethical clearance. This study involved both male and female patients between the age group of 25-40yrs with open fractures of mid shaft tibia, who presented to KIMS Hubli. Patients who had open fractures of tibial mid shaft were treated with wound debridement and interlocking intramedullary nailing with and without reaming during the period from $1 / 08 / 2013$ to $31 / 07 / 2015$. All the cases were fresh fractures and were traumatic in nature. Inclusion criteria: patients with open tibial mid shaft fractures- type I, II, IIIA and IIIB according to Gutillo-Anderson classification patients between the age of 25-40yrs patients managed surgically by Intramedullary inter locking nailing (reamed/unreamed). Exclusion criteria: children with tibial fractures in whom the growth plate is still open, age less than $25 y$ rs and more than $50 y r s$, patients with closed tibial shaft fractures and type IIIC open tibial shaft fractures, associated intraarticular fractures of proximal /distal tibia. 50 patients were followed up for minimum of 6 months. With each follow up, clinical and radiological evaluation was done. Of the 50 patients 25 were treated by reamed and 25 by unreamed intramedullary interlocking nailing. The clinical data collected and evaluated according to Johner-Wruhs' criteria ${ }^{[9]}$, which take functional, clinical, radiological and subjective outcomes into account.

Routine investigations were done for all the patients. All patients were evaluated clinically and radiographically to assess for any other injuries. Radiographs were taken in two planes, A-P and Lateral views. I.V antibiotics, cephalosporins and aminoglycosides were started for all the patients, patients were operated as early as possible, once the general condition of the patients was stable and fit for surgery. At our instituition all patients received iv $3^{\text {rd }}$ generation cephalosporin and an iv aminoglyoside. This was continued till $3^{\text {rd }}$ post-operative day after which IV antibiotics were discontinued and oral $3^{\text {rd }}$ generation cephalosporin was continued for 7 days.

Operative technique- Patients were taken to the operating room for emergency irrigation and debridement of the open fracture. Thorough saline wash was given to the wound and all the foreign bodies over the wound were washed out. The severity of the open fractures determined the subsequent wound care and antibiotic treatment. Wounds were examined and primary closure was done for the wounds presenting within 6 hours of trauma and which were clean. All the patients underwent fracture fixation under spinal/epidural anaesthesia. Patients were placed on the fracture table with the injured leg bent at 90 degrees at the knee with the help of a 
padded attachment and tourniquet for all cases. An anterior midline patellar ligament splitting approach was used for both techniques. Nail length was measured preoperatively and the most commonly used nail diameter was 9 and $10 \mathrm{~mm}$. For the reamed group, reaming was carried out for the entire extent of the medullary canal in a sequence of $0.5-\mathrm{mm}$ increments using flexible reamers. The canal was reamed to $1 \mathrm{~mm}$ more than the diameter of the nail. The appropriate length of the nails that were to be inserted after reaming was determined with use of the guide-rod subtraction method. In the unreamed group, reaming was limited only to the proximal 6 to $8 \mathrm{~cm}$ of the metaphysis to accommodate the proximal flare of the nail. The diameter of the nail was determined by the measurement of the narrowest diaphyseal diameter of anteroposterior and lateral radiograph. Insertion of the nail was controlled under image intensification. Whether to provide static or dynamic locking and the number of interlocking screws were determined according to fracture geometry. Proximal interlocking was carried out with the aid of nail mounted targeting devices, whereas distal interlocking was carried out with a freehand technique under an image intensifier. In the current study, the cannulated tibia nail (CTN) was used in all the 30 cases (both reamed and unreamed cases). The most common nail diameter used was the $9 \mathrm{~mm}$ cannulated tibia nail (CTN). Nail lengths ranged between $300 \mathrm{~mm}$ and $360 \mathrm{~mm}$. The nail length most frequently utilized was $340 \mathrm{~mm}$

Most of the wounds healed by primary coverage but 9 cases 4 in unreamed and 5 in reamed required additional soft tissue procedures in the form of skin grafts 7 cases and flaps for 2 cases.

After 7 days the antibiotics were stopped if there were no signs of infections if there were any signs then culture sensitivity was sent and the antibiotics given accordingly. Postoperatively elastocrepe bandage applied and limb elevation done over pillows. Active knee, ankle and toe mobilization started after the effect of anaesthesia was overcome. Patient was allowed non weight bearing crutch walking in the first week postoperatively both in reamed and unreamed group. Skin sutures, were removed between $10^{\text {th }}$ to $14^{\text {th }}$ postoperative days. Depending upon the culture report and wound condition antibiotics were stopped /continued.

Partial weight bearing with the help of crutches /walker was commenced after 10 days, depending upon the type of fracture and rigidity of fixation in both the groups. Further follow up was done at 6 weekly intervals and each patient was individually assessed clinically and radiographically. Full weight bearing was started when there were signs of clinical and radiological union.

\section{Results}

The average operating time for reamed nailing was 75 minutes and the average operating time for unreamed nailing was 55 minutes. The blood loss for unreamed technique was $50-75 \mathrm{ml}$ and in case of reamed technique it was $100-125 \mathrm{ml}$. The patients were evaluated immediately post op, six weeks, six months and one year after surgery. There were 38 male and 12 female study participants with an average age of 32 years (range, 26-40y). 28 patients had right sided injuries while 22 had left sided injuries, and high velocity motor traffic accidents were the most common cause of injury. Alternating cases were treated with either reamed or unreamed interlocking nailing of the tibia to simulate a randomized controlled trial. There were 22 AO type A fractures, 20 type B and 8 type $\mathrm{C}$ fractures. All fractures were located in the middle third of the tibia. Majority of the open fractures of the tibia were Gustilo type II 36 patients in our study. 9 patients had Gustilo type 1 open fracture. 3 patients had Gustilo type IIIA open fractures. 2 patients had Gustilo type IIIB open fractures. Outcomes including complications encountered, rate of clinical union and rate of radiological union were documented and compared between the reamed and unreamed groups using the Johner and Wruh's criteria ${ }^{[9]}$. There were no significant differences in patient age, gender, mode of injury or overall distribution of fracture types between the reamed and unreamed groups. The average time to clinical union in the reamed group was 22 weeks. Average time to clinical union in the unreamed group was 24 weeks. The average radiological union in the reamed group was seen at 23 weeks. In the unreamed group the average radiological union time was 25 weeks. In the reamed group, out of 25 cases, 10 developed complications. There were 4 cases of superficial infection 6 cases of knee stiffness, ankle stiffness, knee pain. In the unreamed group, out of 25 cases, 09 cases developed complications. There was 2 cases of external rotation deformity, 2 case of knee stiffness and ankle joint stiffness, 2 cases of knee pain, 2 cases of infection of which one was superficial and one deep. 1 case had breakage of the locking screw.

The statistical analysis was done based on the Fisher Exact test Functional results were graded based on Johner and Wruh's criteria ${ }^{9}$. Reamed group- 20 cases had excellent results, 2 cases had good results, 2 cases had fair results and 1 case poor. Unreamed group- - 19 cases had excellent results, 3 cases, had good results, 2 cases had fair result and 1 case a poor result. Secondary procedure-Reamed group dynamisation of the nails were done in 5 of patients usually between 6-10 weeks. Skin grafting was done in 4 patients. One had a crossed leg flap Unreamed group- Dynamisation of the nails was done in 3 of patients usually between 6-10 weeks. Skin grafting was done in 3 patients. In 1 patient soleus flap was done. None of the patients underwent any other procedure like exchange nailing, bone grafting or plating for any of the fractures. 


\section{Unreamed case}

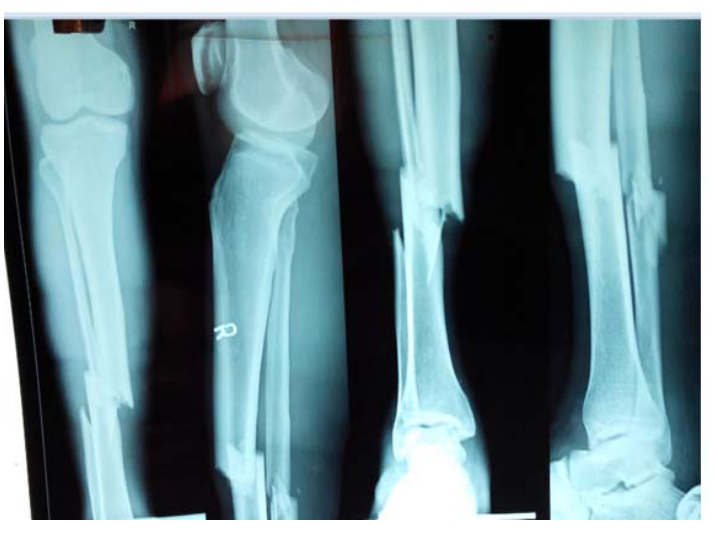

Fig 1: pre-operative x-ray

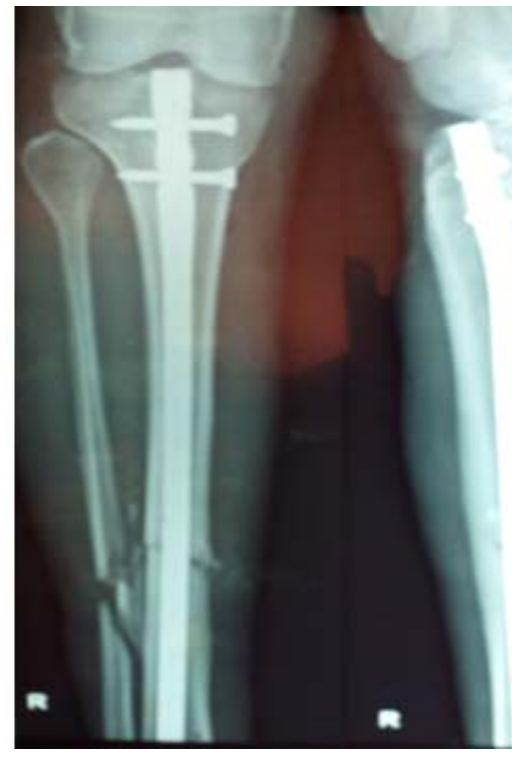

Fig 3: post op x-ray

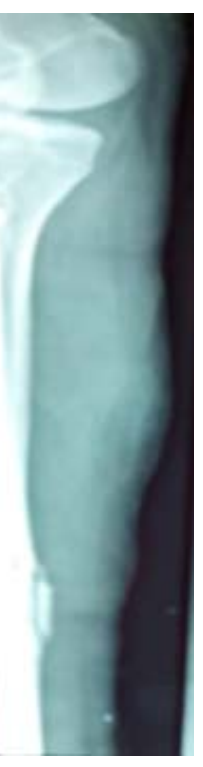

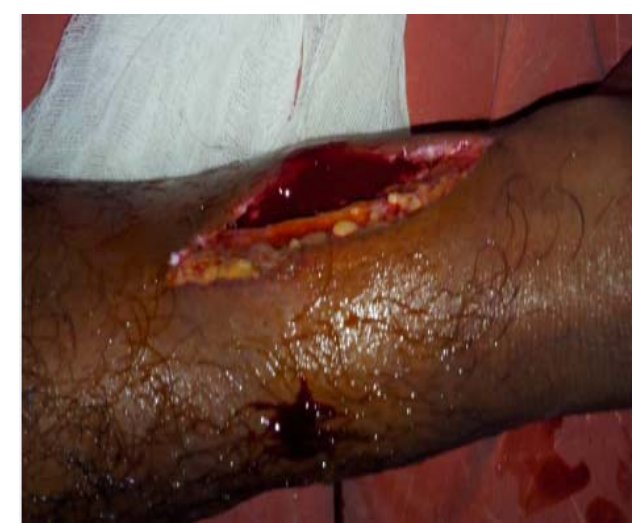

Fig 2: Pre-op wound

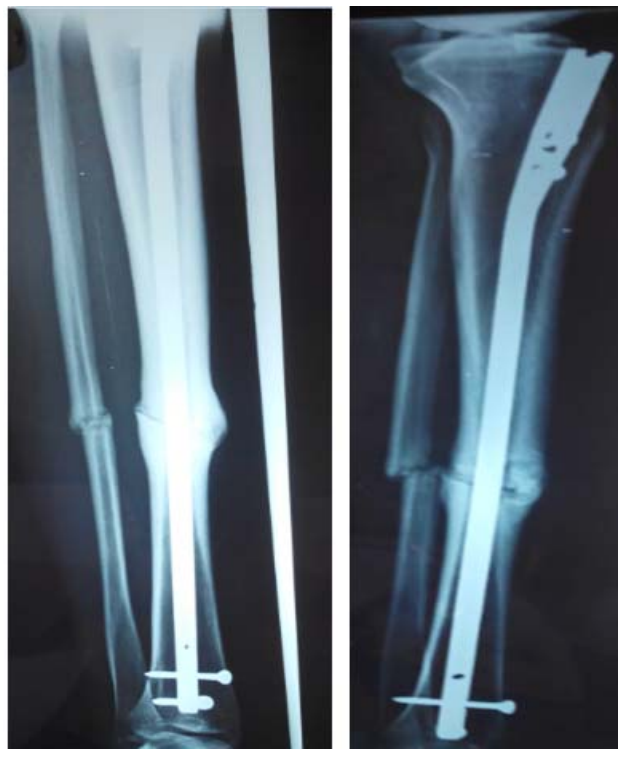

Fig 4: $\mathrm{x}$ ray at 6 month follow up

\section{Reamed case}

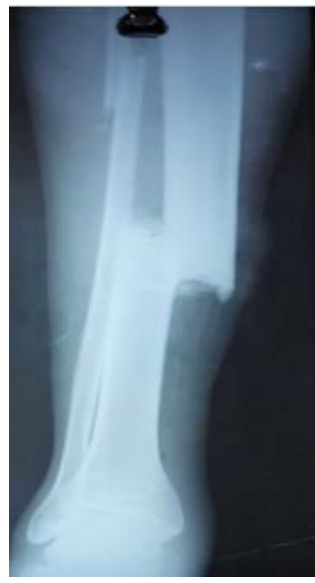

Fig 5: pre op x-ray

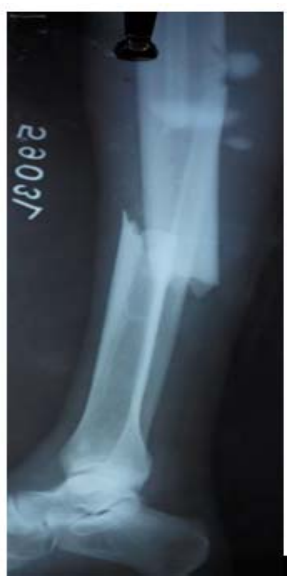




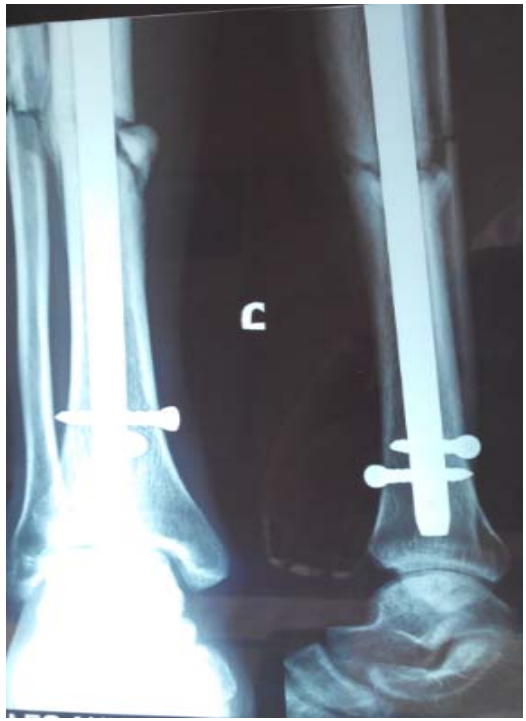

Fig 7: post op x-ray

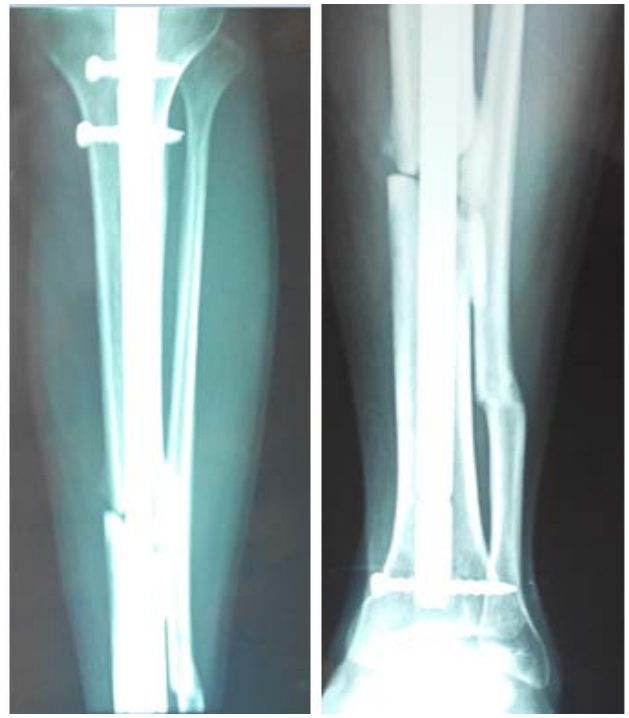

Fig 8: $x$ ray at 6 month follow up

Table 1: For percentage comparison

\begin{tabular}{|c|c|c|c|c|c|c|}
\hline & & & & ults & & Total \\
\hline & & Poor & Good & Fair & Excellent & Total \\
\hline \multirow{4}{*}{ Technique } & \multirow{2}{*}{ Reamed } & 1 & 2 & 2 & 20 & 25 \\
\hline & & $04 \%$ & $08 \%$ & $08 \%$ & $80 \%$ & $100.0 \%$ \\
\hline & \multirow{2}{*}{ Unreamed } & 1 & 3 & 2 & 19 & 25 \\
\hline & & $04 \%$ & $12 \%$ & $08 \%$ & $76 \%$ & $100.0 \%$ \\
\hline \multirow{2}{*}{\multicolumn{2}{|c|}{ Total }} & 2 & 5 & 4 & 39 & 50 \\
\hline & & $04 \%$ & $10 \%$ & $08 \%$ & $78 \%$ & $100.0 \%$ \\
\hline
\end{tabular}

$\mathrm{P}=0.114 *$ not significant Fisher Exact test

Table 2: Anatomical parameters of atlas

\begin{tabular}{|c|c|c|c|}
\hline & Total & Reamed & Unreamed \\
\hline 1 Gender & 38 & 20 & 18 \\
Male & 12 & 05 & 07 \\
Female & 28 & 16 & 12 \\
\hline 2 Affected Limb & 22 & 09 & 13 \\
Right & 09 & 04 & 05 \\
Left & 36 & 20 & 02 \\
\hline 3 Gustillo Type & 03 & 01 & 02 \\
I & 02 & 00 & 02 \\
Ii & & & 01 \\
Iiia & 06 & 04 & 01 \\
Iiib & 01 & 00 & 07 \\
4 Complications & 01 & 00 & 02 \\
Infections & 13 & 06 & 02 \\
Non-Union & 04 & 02 & \\
Screw Breakage & & & 02 \\
Stiffness & &
\end{tabular}

\section{Discussion}

The optimal management of open tibial shaft fractures continues to be a problem with several unanswered questions. These fractures which are usually caused by high energy trauma, have numerous problems resulting from the poor soft tissue coverage and limited vascular supply of the tibia. The open fractures may lead to malunion, non-union, infections and sometimes result in amputations. Recent improvements in wound coverage techniques and fixation devices have decreased the prevalence of these complications, but the optimum management of open tibial shaft fractures is still evolving ${ }^{10}$. The major factors affecting the prognosis of open tibial fractures after high-energy trauma are the severity of soft-tissue injuries, degree of contamination and fracture configuration ${ }^{[11]}$.

The second factor is the damage of the tibial blood supply. In open fractures, not only is the endosteal circulation disrupted but also there is periosteal circulation disruption after severe soft tissue damage and periosteal stripping from the bone. This emphasises the necessity to preserve as much as possible the vascularity of the endosteal vessels, using stabilisation technique that avoid additional disruption of this blood supply. Intramedullary fixation of tibial shaft fractures has gained popularity in recent years with the development of interlocking nails. This technique is currently used to stabilize unstable diaphyseal tibial fractures. However, differing surgeons advocate two different methods of nail insertion, i.e., with and without reaming of the medullary canal. Each method has 
specific advantages and disadvantages and controversy still continues regarding which method is warranted for specific clinical situations.

Of the various intramedullary devices available, the unreamed unlocked nails have produced good results in open tibial fractures but the implant did not adequately stabilise the comminuited or segmental fractures. In 29 open tibial shaft fractures treated with Ender nails, the authors ${ }^{[12]}$ reported a $7 \%$ rate of infection and a $21 \%$ rate of malunion. Until recently; nails used without reaming could not be locked to the major fracture fragments, but the recent development of locked unreamed intramedullary nails have eliminated this problem.

In unreamed nailing, there is less risk of fat embolism and several studies suggest better preservation and more-rapid recovery of the intraosseous blood supply after insertion of a small-diameter nail without reaming ${ }^{[13,14]}$. In contrast, studies by Blachut et al. and Court Brown et al. seem to indicate that nonunion occurs more frequently with unreamed nail. Some studies indicate increased incidence of screw and nail breakage with unreamed nailing.

Interlocking intramedullary nailing with reaming solves the problem of malunions because it provides the ability to control length, angulation and rotation but is associated with high risk of infection in open tibial fractures. However, reaming result in destruction of all vessels in the medullary canal and increases in medullary pressure which leads to infiltration of medullary fat, blood clots and bone debris into the vascular channels. This destruction of endosteal blood vessels along with already compromised vascular supply due to periosteal stripping and soft tissue damage causes considerable bone necrosis and accounts for high rate of infection and non-union in open tibial shaft fractures ${ }^{[15]}$.

The author ${ }^{16}$ found 33 percent rate of infection in a series of 18 open tibial shaft fractures treated with intramedullary nailing with reaming, most of the fractures were associated with severe soft tissue injury. Some truamatologists believe that intramedullary nailing with reaming may be used safely for fractures with less severe wounds.

The authors evaluated the cortical blood supply of canine tibiae after nailing with and without reaming ${ }^{17}$. They found that reaming disrupts an average of $70 \%$ of the cortical blood supply, while insertion of a nail without reaming disrupts the blood supply only by $30 \%$. This is especially important in the treatment of open fractures in which the outer cortical blood supply may be damaged by periosteal stripping.

While reaming can cause devascularisation of the cortex and thermal necrosis of the inner $50-70 \%$ of the cortex ${ }^{18,19}$ thus delaying healing, it can also help to fix the fracture with a larger size nail thus achieving better stability ${ }^{[20,21,22]}$. Studies have also suggested that reamed nailing results in early union rates and decreased incidence of delayed union, malunion and non-union.

The effects of reaming on fat embolism should also be considered. Reaming of open fractures has been found to spread the contamination from open wound along the medullary cavity and to strip small fragments of bone from the soft tissue attachment ${ }^{[23]}$. Systemic changes of reaming have to be considered these include pulmonary embolization, temperature-related changes of the coagulation system, neural and inflammatory reactions.

In our study in the reamed group majority of the open fractures of the tibia were Gustilo type II 10 patients (33.33\%) of which 7 had excellent functional outcome 2 had good and 1 had fair outcome. 4 patients $(13.33 \%)$ had Gustilo type 1 open fracture of which all 4 had excellent outcome. 1 patient $(3.33 \%)$ had Gustilo type IIIA open fractures who had poor result. In the unreamed group- 6 patients $(20 \%)$ were Gustilo type II open fractures out of which 5 had excellent results an one good result. 5 patients $(16.66 \%)$ had Gustilo type 1 open fracture out of which all 5 had excellent results 2 patients $(6.66 \%)$ had Gustilo type IIIA open fractures one had excellent result and one good result. 2 patients $(6.66 \%)$ had Gustilo type IIIB open fracture one had fair result and one poor result.

The biggest study of the effects of reaming was undertaken by the SPRINT group in the USA, Canada and the Netherlands. They analysed 1226 patients who were randomised to reamed or unreamed nailing of their tibial diaphyseal fractures. In the tibial fractures, $11 \%$ of the reamed group and $17 \%$ of the unreamed group experienced a 'primary event', which was a significant complication. The main difference between the two procedures related to a statistically significant increase in the number of bent or broken cross screws in the unreamed group. There was no difference in the use of exchange nailing to treat non-union. In the open fracture group there was no difference between reamed and unreamed nails.

Table 3: Table showing the comparison of Keating et al., Blachut et al. and our study

\begin{tabular}{|c|c|c|c|c|c|c|}
\hline & \multicolumn{2}{|c|}{ Keating et al. study } & \multicolumn{2}{c|}{ Blachut et al. study } & \multicolumn{2}{c|}{ Our study } \\
\hline & Reamed & Unreamed & Reamed & Unreamed & Reamed & Unreamed \\
\hline No of patients & 47 & 41 & 70 & 56 & 25 & 25 \\
\hline Union rate & $91 \%$ & $88 \%$ & $95 \%$ & $89 \%$ & $100 \%$ & $96 \%$ \\
\hline Non-union rate & $9 \%$ & $12 \%$ & $5 \%$ & $11 \%$ & $0 \%$ & $04 \%$ \\
\hline Mal union rate & $4 \%$ & $2 \%$ & $4.1 \%$ & $3.2 \%$ & $08 \%$ & $08 \%$ \\
\hline Infection rate & $4.3 \%$ & $2.4 \%$ & $0 \%$ & $1.6 \%$ & $16 \%$ & $08 \%$ \\
\hline Screw breakage & $9 \%$ & $29 \%$ & $2.7 \%$ & $16 \%$ & $0 \%$ & $04 \%$ \\
\hline Nail failure & $4.3 \%$ & $2.4 \%$ & 0 & $1.4 \%$ & $0 \%$ & $0 \%$ \\
\hline
\end{tabular}

\section{Conclusion}

1. Intramedullary nailing is the proven choice of treatment for adult tibial shaft fractures, despite the fact that controversy exists regarding the choice of reamed or unreamed intramedullary nailing. There are no clear indications or contraindications for choosing either option. Clinical and radiographic results of nailing after reaming are similar to those of nailing without reaming for fixation of open fractures of the tibial shaft. The over-all time to union was similar between the two groups, with no evidence that reaming delays the process of union. Operative care of the soft tissue wound is critical in the treatment of open fractures. Adequate debridement of the soft tissue and bone followed by adequate soft tissue coverage is the key to minimize deep infection after these injuries, irrespective of whether the bone is reamed or not, which is the outcome of present study. Considering the ease of performing the technique and the decreased operative time, unreamed interlocking nailing may have an edge over reamed interlocking nailing. 
Patient characteristics had no statistically significant influence on fracture healing. The mechanism of injury, however, was influential in fracture union and patient outcome. High-energy fractures had a significantly longer time to union and a higher rate of delayed union, nonunion, and malunion.

2. Early mobilisation of the patients in both reamed and unreamed cases helps in healing of the fracture and prevents joint stiffness.

3. Earlier soft tissue coverage, fracture dynamisation at $6-10$ weeks if union does not progress to prevent the unwanted complications of non-union or delayed union are some of the advantages of nailing (reamed or unreamed). We are also of the opinion that ideally locking all the proximal and distal holes avoids malunions and fatigue of locking bolts.

\section{References}

1. Bucholz, Heckman's. Rockwood Greens: Fractures in Adults, edition, Lipincott Williums and Wilkins Company, USA, pages 1939-1994, 2001, 2:5.

2. Terry Canale's CAMPBELL'S OPERATIVE ORTHOPAEDICS $10^{\text {th }}$ edition, Mosby publishers, 2003; 3:2754-2782.

3. Charley J. fractures of the shaft of tibia. The closed treatment of common fractures, Edinburg, Churchill Livingstone, 1961, 209-249.

4. Holbrook JL, Swiontiowski MF, Sanders R. treatment of open fractures of the tibial shaft: Ender nailing versus external fixation; a randomised prospective comparison". J Bone Joint Surg, 1989; 71A:1231-1238.

5. Swanson TV, Speigel JD, Sutherland TB, Bray TJ, Chapman MW. A prospective, comparative study of the Lottes nail versus external fixation in 100 open tibial fractures. Orthop Trans. 1990; 14:716-717.

6. Blachut PA, O'Brien PJ, Meek RN, Broekhuyse HM. Interlocking Intramedullary nailing with and without reaming for the treatment of open fractures of the tibial shaft. A prospective randomized study. J Bone Joint Surg Am. 1997; 79(5):640-6.

7. Fairbank AC, Thomas D, Cunningham B, Curtis M, Jinnah RH. Stability of reamed and unreamed intramedullary tibial nails: a biomechanical study. Injury 1995; 26:483-485.

8. Rhinelander FW. tibial blood supply in relation to fracture healing. Clin Orthop, 1974; 105:34-81.

9. Johner R, Wruhs O. Classification of tibial shaft fractures and correlation with results after rigid internal fixation. Clin Orthop Relat Res. 1983; 178:7-25.

10. Whittle AP, Russell TA, Taylor JC, Lavelle DG. Treatment of open fractures of the tibial shaft with the use of interlocking nailing without reaming. J Bone Joint Surg, 1992; 74A:1162-1171.

11. Hoaglund FT, States JD. Factors influencing the rate of healing in tibial shaft fractures. Surg Gynecol Obstet. 1967; 124:71-6.

12. Holbrook JL, Swiontiowski MF, Sanders R. treatment of open fractures of the tibial shaft: Ender nailing versus external fixation; a randomised prospective comparison. J Bone Joint Surg. 1989; 71A:1231-1238.

13. Anglen JO, Blue JM. A comparison of reamed and unreamed nailing of the tibia. J Trauma. 1995; 39(2):3515.

14. Gaebler C, Berger U, Schandelmaier P, Greitbauer M, Schauwecker HH, Applegate B et al. Rates and odds ratios for complications in closed and open tibial fractures treated with unreamed, small diameter tibial nails: a multicenter analysis of 467 cases. J Orthop Trauma. 2001; 15(6):415-23.

15. Rhinelander FW. Effects of medullary nailing of the normal blood supply of diaphyseal cortex, Clin Orthop, 1998; 350:5-17.

16. Smith JE. Results of early and delayed internal fixation for tibial shaft fractures: A review of 470 fractures. J Bone Joint Surgery (Br). 1974; 56-B:469-477.

17. Moed BR, Watson JT, Goldschmidt P, Holsbeeck MV. Ultrasound for the early diagnosis of fractures healing after interlocking nailing of the tibia without reaming. Clin Orthop, 1995; 310:137-144

18. Leunig M, Hertel R. Thermal necrosis after tibial reaming for intramedullary nail fixation: A report of three cases. J Bone Joint Surg Br. 1996; 78(4):584-7.

19. Watson JT. Treatment of unstable fractures of the shaft of the tibia. J Bone Joint Surg Am. 1994; 76(10):1575-84.

20. Koval KJ, Clapper MF, Brumback RJ, Ellison PS, Jr, Poka A, Bathon GH et al. Complication of reamed intramedullary nailing of tibia. J Orthop Trauma. 1991; 5(2):184-9.

21. Finkemeier CG, Schmidt AH, Kyle RF, Templeman DC, Varecka TF. A prospective, randomized study of intramedullary nails inserted with and without reaming for the treatment of open and closed fractures of the tibial shaft. J Orthop Trauma. 2000; 14(3):187-93.

22. Larsen LB, Madsen JE, Høiness PR, Øvre S. Should insertion of intramedullary nails for tibial fractures be with or without reaming? A prospective randomized study with 3.8 year's follow up. J Orthop Trauma. 2004; 18(3):144-9.

23. Kessler SB, Hallfeldt KK, Perren SM, Schweiberer L. The effects of reaming and intramedullary nailing on fracture healing. Clin Orthop. 1986; 212:18-25. 